\title{
Perceptions of specialist doctors of the ability of doctors with colour vision deficiency to practise their specialty safely
}

\author{
UPREET DHALIWAL, SATENDRA SINGH, GAURAV NAGPAL, AANCHAL KAKKAR
}

\begin{abstract}
Some doctors with severe congenital colour vision deficiency (CCVD) may experience difficulty in colour discrimination that can affect their decision-making. In the absence of evidencebased guidelines, learners with CCVD are arbitrarily debarred from specialising in some disciplines. This cross-sectional, anonymous, questionnaire-based study asked specialists from all over the country if doctors with CCVD should avoid specialising in their respective disciplines. Of 218 responses, 80 (36.7\%) said they should avoid it, citing colour discrimination as critical. The 32 (14.7\%) participants who were unsure and 106 (48.6\%) who said that CCVD would not be a problem gave reasons that mirrored those in the literature: the degree of deficiency is variable; experience helps; automation, history-taking, close observation, good illumination, contrast, touch, and peer-corroboration can reduce dependency on colour. Awareness of the deficiency and finding ways to compensate for it during training may mitigate errors and safeguard patients. Instead of blocking people with CCVD from admission to some specialties, specialists should consider these findings and support learners who are aware of their deficiency and still wish to specialise in a particular discipline.
\end{abstract}

Keywords: colour vision defects, congenital colour vision deficiency, patient safety, physician impairment, reasonable accommodation

Authors: Upreet Dhaliwal (corresponding author - upreetdhaliwal@ yahoo.com), Former Director-Professor, Dept of Ophthalmology, and Founding Member, Health Humanities Group, University College of Medical Sciences, Delhi 110095 INDIA; Satendra Singh (dr.satendra@gmail.com), Associate Professor, Dept of Physiology, and Founding Member, Health Humanities Group, University College of Medical Sciences, Delhi, 110095 INDIA; Gaurav Nagpal (drgnagpal@gmail.com), Consultant, Radium Eye Centre, A1/11, 3rd floor, Sector 8, Rohini, Delhi 110085 INDIA; Aanchal Kakkar (kakkaraanchal2@gmail.com), Assistant Professor, Department of Anaesthesia and Critical Care, RML Hospital, Delhi 110001, INDIA.

To cite: Dhaliwal U, Singh S, Nagpal G, Kakkar A. Perceptions of specialist doctors of the ability of doctors with colour vision deficiency to practise their specialty safely. Indian J Med Ethics. 2020 Oct-Dec; 5(4)NS: 268-77. DOI: 10.20529/IJME.2020.110.

Manuscript Editor: Olinda Timms

Peer Reviewers: Samiran Nundy, Uma Kulkarni

() Indian Journal of Medical Ethics 2020

\section{Introduction}

Colour is an important diagnostic criterion in many clinical and laboratory situations (1-5). The literature shows that doctors with colour vision deficiency (CVD) may experience difficulties in colour discrimination during practice; conversely, it is also seen that over time they are able to perform reasonably well by using other important clues (68). In India, students with congenital colour vision deficiency (CCVD) are not debarred from joining the undergraduate medical course; thereafter, in the absence of uniform guidelines on their fitness to join a postgraduate course, they may face a stumbling block when a postgraduate admissions committee debars them on the grounds of their having a deficiency in colour vision. In the absence of evidence-based guidelines, decisions to debar them from joining a specialisation of their choice are based on arbitrary grounds and are made by specialists who do not themselves have CCVD. These decisions risk being challenged in the courts (9). This study seeks to examine what specialists perceive about the issue of students with CCVD joining medicine and whether they feel that CVD could hamper practice in their particular specialty. The study might help in formulating an advisory for students with CVD until a better-informed advisory can be prepared, once more physicians with CVD come forward without fear of stigma to share their experiences.

\section{Methods}

This was a cross-sectional, observational, online study using a questionnaire, conducted from June 2018 to March 2019. Specialists from all disciplines were recruited through social media, from medical education and other listservs and through email, using a flyer. They were requested to complete the questionnaire only if they fulfilled all three inclusion criteria: had completed their post-graduation; were working in the field of their specialisation for at least eight years after post-graduation; and were based in India. The flyer detailed the need for the study and the procedures involved. Participants were directed via a link to a questionnaire on Google forms that sought to assess, among other things, their perceptions on whether CCVD could hamper practice in their own specialty. Overall, less than 10 minutes of participation was required at a time that suited their convenience. 


\section{Sample size}

For the purpose of calculating sample size, we considered respondents as belonging to one of three groups: Pre- and Para-clinical (PP: Anatomy, Physiology, Biochemistry, Pathology, Pharmacology, Forensic Medicine, and Microbiology), Medical specialties (MM: Community Medicine, General Medicine, Dermatology, Radiology, Psychiatry, Paediatrics, and Anaesthesiology) and Surgical specialties (SS: Ophthalmology, Otorhinolaryngology, General Surgery, Obstetrics \& Gynaecology, and Orthopaedics).

In the absence of historical data, we took the chance that $50 \%$ of respondents might say that learners with CCVD should not join their specialty. Thus, keeping $10 \%$ absolute error as acceptable, the sample size for each group was calculated to be at least 100 . However, since there are generally fewer faculty in the pre- and para-clinical streams, and there are fewer broad specialties in surgical as compared to medical disciplines, we determined that we needed to recruit 75 respondents from PP, 75 from SS, and 100 from MM specialties (Total 250 respondents).

\section{Ethics}

Waiver of ethics clearance was received from the authors' institutions in view of the online method of data collection where identifying data and face-to-face interaction was not sought (IEC-HR/2018/33/3/ and 242(16/2018)/IEC/PGIMER/ RMLH/718/18). The study was thus completely confidential. There was no risk involved for the participants, and they were free to withdraw from the research at any time, without any penalty. The data was securely downloaded and maintained in a password-protected Excel document.

\section{Data analysis}

A descriptive analysis was done: proportions, averages, and standard deviations were calculated using SPSS version 16. Association between responses (Yes/No) and the different items of the questionnaire were determined using the Chisquare and Fisher Exact test.

\section{Results}

The number of respondents was 251, of whom 218 (86.9\%) fulfilled all three eligibility criteria. The responses of the 218 participants with respect to the primary objective - should medical students with CCVD join their specialty? [should not: $\mathrm{n}=80$ (36.7\%); unsure: $\mathrm{n}=32$ (14.7\%); should join: $\mathrm{n}=106$ (48.6\%)] - were found to be comparable with those of the 33 who did not fulfill all three criteria [should not: $\mathrm{n}=9(27.3 \%)$; unsure: $n=2(6.1 \%)$; should join: $n=22(66.7 \%) ; p=0.15)$ ]. Nevertheless, we chose to stay committed to the original inclusion criteria; thus, the following results pertain to 218 respondents. Of some interest was one ineligible respondent who did not continue in the profession after graduating because of CCVD. The observations of this participant (Respondent- $\mathrm{X}$ ) are also presented.
There were 65 respondents $(29.8 \%)$ from the PP specialties $[$ Anatomy $=8$, Biochemistry $=11$, Physiology $=17$, Pathology $=$ 12 , Microbiology $=5$, Pharmacology $=7$, and Forensic medicine and Toxicology $=7$ ]. MM comprised 86 (39.5 \%) respondents [Community Medicine $=9$, General medicine $=5$, Paediatrics $=11$, Anaesthesia $=35$, Dermatology $=6$, Psychiatry $=1$, Radiology $=6$, Superspecialties $=13]$. SS [Ophthalmology $=19$, Otorhinolaryngology $=9$, General surgery $=8$, Obstetrics and Gynaecology $=15$, Orthopaedics $=6$, Superspecialties $=10$ ] had 67 (30.7\%) respondents.

One person in each broad group had been diagnosed with CCVD (one Forensic Medicine specialist, one paediatrician, and one ophthalmologist). In addition, three people (an anatomist, a biochemist, and a microbiologist) in group PP, and a paediatrician in group MM suspected that they might be colour vision deficient (CCVD-unconfirmed) but had not got themselves tested.

Based on their own experience during the medical course, only $33(15.1 \%)$ participants felt that students with CCVD should avoid it. Respondent- $X$, too, shared that opinion. Most others ( $n=140 ; 64.2 \%$ - including two of the three doctors with CCVD and all four CCVD-unconfirmed opined that they should be allowed to join, while $45(20.6 \%$ - including the Forensic Medicine specialist with (CVD) said they were not sure about it.

When asked if, based on their experience in their own specialty, students with CCVD should avoid taking up their specialty, overall, 106 (48.6\%) respondents thought they should specialise in it if interested. Eighty (36.7\%) respondents said no, while $32(14.7 \%)$ said they were unsure. The reasons they gave for their choices are summarised in Table 1. Some respondents gave no reason.

Nearly half $(106 ; 48.6 \%)$ of the respondents felt that, over time or with training, doctors with CVD could learn to use colour-independent cues (like detailed history, brightness and contrast, close observation, touch, etc.) to avoid errors in their particular specialty. This included two CCVD-unconfirmed (a microbiologist and a paediatrician) and all three respondents who were diagnosed with CCVD. More than one-third of the respondents $(80 ; 36.7 \%)$ were unsure about the potential for this [including two CCVD-unconfirmed (an anatomist and a biochemist), and Respondent X].

When asked whether they would be comfortable if their diagnostic report was signed by a microbiologist / pathologist / biochemist / haematologist / radiologist with CCVD, many said no $(126 ; 57.8 \%)$ and $41(18.8 \%)$ were unsure. On the other hand, when asked whether they would be comfortable if they knew that their treating physician had CVD, about half said yes (110; 50.5\%), while $32(14.7 \%)$ were unsure. Finally, with respect to CCVD surgeons, 122 (56.0\%) said they would not be comfortable if their treating surgeon had CCVD, while $36(16.5 \%)$ felt unsure. Their reasons, paraphrased for brevity, are displayed in Tables 2-4. Some respondents gave no reason. 


\begin{tabular}{|c|c|}
\hline \multicolumn{2}{|r|}{$\begin{array}{l}\text { Table 1: } \\
\text { Reasons given by respondents for why a medical student with colour vision deficiency should avoid training in their specialty }\end{array}$} \\
\hline Response & $\begin{array}{l}\text { Based on your experience in YOUR OWN specialty, what are the reasons that you feel a medical student with color vision } \\
\text { deficiency should avoid specialising in it? } \\
\text { (Specialty of respondent) }\end{array}$ \\
\hline $\begin{array}{l}\text { It won't be a } \\
\text { problem, the } \\
\text { student should } \\
\text { specialise if } \\
\text { interested }\end{array}$ & $\begin{array}{l}\text { Colour discrimination is not a critical requirement (Physiology, Pharmacology, Community medicine, Pulmonary medicine, } \\
\text { Ophthalmology, Gastrointestinal surgery, Vascular surgery) } \\
\text { There are no/limited patient care activities (physiology, pharmacology) } \\
\text { Does not need to identify very subtle differences in colour (Paediatrician with CCVD, Anaesthesia, Otolaryngology, Obstetrics } \\
\text { and Gynaecology) } \\
\text { Needs mainly technical skills (Anaesthesia) } \\
\text { Colour is irrelevant because of automation, audible monitors, pattern and morphological cues, and newer diagnostic modalities. } \\
\text { (Biochemistry, Pathology, Pharmacology, Paediatrics, Anaesthesia, Radiology, Radiation oncology, Ophthalmology) } \\
\text { Depends on type of deficiency (Forensic medicine specialist with CCVD, General surgery) } \\
\text { Adapts to perceiving colours in a different way (Forensic medicine, Dermatology, Ophthalmology) } \\
\text { Uses additional cues or techniques (Forensic medicine, Paediatrics, Anaesthesia, Obstetrics and Gynaecology) } \\
\text { Can develop perception over time through repeated practice (Microbiologist CCVD-unconfirmed, Paediatrics) } \\
\text { Can avoid/take particular care during specific tasks requiring colour discrimination (Anatomy, Physiology, Pharmacology, } \\
\text { Paediatrics, Dermatology, Ophthalmology) } \\
\text { Have seen students/friends/surgeons/colleagues with CCVD practicing safely (Physiology, Anaesthesia, Psychiatry, Cardiology, } \\
\text { Otolaryngology, General surgery, Orthopaedics) } \\
\text { No reason given (Paediatrician CCVD-unconfirmed) }\end{array}$ \\
\hline I cannot say & $\begin{array}{l}\text { No reason given (Anatomist CCVD-unconfirmed, Ophthalmologist with CCVD) } \\
\text { Specialise only where colour discrimination is not required (Physiology) or in non-surgical branches (Orthopaedics) } \\
\text { The degree of the CVD will determine this (Pathology, Dermatology) } \\
\text { Will depend on the particular situation (Community medicine) } \\
\text { I cannot say what difficulties will occur (Dermatology, General Surgery, Obstetrics, and Gynaecology) } \\
\text { May be able to adjust over time (General surgery) }\end{array}$ \\
\hline $\begin{array}{l}\text { Should NOT } \\
\text { specialise in it }\end{array}$ & $\begin{array}{l}\text { There will be difficulty in certain areas or tasks: } \\
\text { coloured diagrams, dissection, living anatomy, microanatomy, histology (Anatomy); } \\
\text { colour changes of chemicals, fluorescent dyes, stains (Biochemistry, Pathology, Forensic medicine); } \\
\text { identifying colour/colour change in clinical situations (Biochemist CCVD-unconfirmed, Physiology, Forensic medicine, General } \\
\text { medicine, Paediatrics, Anaesthesia, Dermatology, Gastroenterology, Rheumatology, Ophthalmology, Otorhinolaryngology, } \\
\text { General surgery, Obstetrics \& gynaecology, Orthopaedics, Neurosurgery, Surgery and transplant, Plastic surgery, Endourology); } \\
\text { identifying blood/bleeding (General medicine, Gastroenterology, Otorhinolaryngology, General surgery, Obstetrics and } \\
\text { Gynaecology, Orthopaedics, Neurosurgery); } \\
\text { antemortem versus postmortem changes / age estimation of injuries (Forensic medicine); } \\
\text { colour alarms of monitors and ventilators / colour codes for medicines, inhalational gases (Anaesthesia); } \\
\text { diagnostic investigations (Radiology, Ophthalmology); } \\
\text { performing surgery (Otorhinolaryngology, General surgery, Obstetrics and Gynaecology, Orthopaedics, Neurosurgery) }\end{array}$ \\
\hline
\end{tabular}

Based on their experience during their MBBS postings in the various departments, respondents were asked to indicate all the specialties that they thought a doctor with CCVD could have difficulty in. They were requested to select all that they thought were applicable. Their choices are displayed in Table 5.

\section{Discussion}

We recruited physicians from all over the country to give their opinion on whether a person with CCVD would be able to perform in their specialty or not. Ideally, such a study should have involved people with CCVD, and we had hoped that, since their identity was not solicited, many such doctors would respond. That was not the case; however, while seven is a disappointingly small number, the proportion is not unexpected - at about 3.2\% (7/218 eligible respondents; $8 / 251$ total respondents), this compares well with a previous study on medical students, where the prevalence of CCVD was found to be $3.4 \%$ of the 1022 students screened by the Ishihara test (1).

We were intrigued about why the four doctors who suspected they had CCVD had not got themselves tested. It highlights that all universities do not mandate testing during admission to the course. Why the respondents did not voluntarily ask for testing may be due to the stigma associated with the diagnosis; the fact that they were managing fine in practice and felt no need to get labeled; or, perhaps, the test was not easily accessible where they practised (10-12). Since we did 
Table 2:

Reasons given by respondents who did not want their diagnostic or treating physician or their surgeon to have CCVD

\begin{tabular}{|c|c|}
\hline $\begin{array}{l}\text { I would NOT be } \\
\text { comfortable if my }\end{array}$ & Reason \\
\hline $\begin{array}{l}\text { diagnostic report was } \\
\text { signed by a doctor with } \\
\text { colour vision deficiency }\end{array}$ & $\begin{array}{l}\text { It may be to the best of their ability, but it may not be correct }(n=8) \\
\text { Won't be able to interpret slides }(n=9) \\
\text { A Doppler report may not be readable by a person with CVD } \\
\text { May be unable to detect what is there, or mistakenly identify something that is not there }(n=7) \\
\text { My Gram Stain or pathology report should be seen by someone who can see blue and pink } \\
\text { Especially not comfortable with pathology and microbiology }(n=2) \\
\text { Quality of service may suffer } \\
\text { These fields have inherent diagnostic pitfalls. CVD will add another confounding factor } \\
\text { The doctor has to be sure of himself } \\
\text { Colour perception may affect diagnosis (CCVD-unconfirmed Biochemist) }\end{array}$ \\
\hline $\begin{array}{l}\text { treating physician had } \\
\text { colour vision deficiency }\end{array}$ & $\begin{array}{l}\text { May be unable to identify clinical signs or interpret reports; may miss the diagnosis or make errors ( } n=8) \\
\text { May not be able to appreciate jaundice, anaemia, hemorrhage etc. }(n=2) \\
\text { May not be able to quantify and monitor change in some coloured signs over time } \\
\text { I know it is a handicap in medicine and I would not choose a physician with CCVD }(n=2)\end{array}$ \\
\hline $\begin{array}{l}\text { treating surgeon had } \\
\text { colour vision deficiency }\end{array}$ & $\begin{array}{l}\text { May miss important colour clues during surgery }(n=6) \\
\text { He may not identify some anatomical structure by colour and may accidentally cut it } \\
\text { Need colour vision for tissue differentiation }(n=2) \\
\text { May not be able to differentiate an artery from a vein, or vessels from nerves }(n=3) \\
\text { May not be able to perceive blood or detect bleeders }(n=6) \\
\text { Surgeons make real time decisions; have little time to look for other clues } \\
\text { Damage may be done before the surgeon gains experience about other cues } \\
\text { In vascular surgery and microsurgery, precision is of utmost important } \\
\text { Difficult to pick up and monitor colour changes in wounds } \\
\text { Prone to make diagnostic error ( } n=5) \\
\text { Do not wish to put myself at unnecessary risk of complications }(n=2)\end{array}$ \\
\hline
\end{tabular}

not record identifying data in the questionnaire, it was not possible for us to inquire after the real reason, nor could we confirm through testing if they indeed had CCVD, so we thought it best not to speculate any further on this aspect.

\section{Respondents' views on people with CCVD in medicine CCVD and the undergraduate course}

As far as people with CCVD joining the medical course was concerned, only $15 \%$ were unequivocally opposed to it. Of the eligible doctors with CCVD/CCVD-unconfirmed, six out of seven endorsed their inclusion in the course, while one was uncertain. Respondent-X, however, opposed it. This was a person who had changed professions because of the CCVD. It is impossible to say what motivated the move out of medicine, but some thoughts are: he may have had a greater severity of CVD; may have faced stigma during the course; may not have been offered positive counseling or mentoring, or, on the contrary, may have received advice to quit; he and/or his teachers may not have known about the concept of reasonable accommodation for the congenital deficiency $(2,5,7,10,13)$. Reasonable accommodation, a relatively recent concept in the Indian consciousness, refers to making appropriate degrees of adjustments, within reasonable limits that do not burden the institution/department/faculty, so that learners with CCVD are able to mitigate any disadvantage due to their disability (12). Indeed, teachers could assist learners in finding ways to use cues other than colour (contrast, morphology, texture, etc) early in the medical course $(7,14)$. We speculate that Respondent- $X$ might have stayed on in the profession if support and reasonable accommodation had been provided, assuming that he would have been open to declaring his condition to the faculty. For all we know, he might have ended up doing very well as a medical practitioner (7).

\section{CCVD and the postgraduate course}

The same optimism was not seen when it came to specialty choices - only about half the respondents believed their specialty would be viable for learners with CCVD to practise in. The reasons they gave were illuminating. Broadly, the naysayers stated that it would cause difficulty in recognising coloured cues and colour changes (in the laboratory, in clinics, on alarms and monitors, and during surgery), including in the diagnosis of bleeding. The impression was that colour was paramount in the practice of medicine. It certainly is, but diagnosis is a complex process and involves many other factors apart from colour $(5,15)$; besides, there are ways to circumnavigate the limitations which have been described in the literature and 


\begin{tabular}{|c|c|}
\hline & $\begin{array}{l}\text { Table 3: } \\
\text { Reasons given by respondents who were uncertain about } \\
\text { eir comfort with their diagnostic or treating physician or their surgeon having CCVD }\end{array}$ \\
\hline $\begin{array}{l}\text { Not a clear-cut yes/no for } \\
\text { me how comfortable l'd } \\
\text { be if my - }\end{array}$ & Reason \\
\hline $\begin{array}{l}\text { diagnostic report was } \\
\text { signed by a doctor with } \\
\text { colour vision deficiency }\end{array}$ & $\begin{array}{l}\text { I do not know what a colour blind person can see; is the person unable to see colour at all or see it as a different shade? } \\
\text { ( } n=3 \text { ) } \\
\text { People with CVD have already allocated a particular shade to every colour. They may not see red as red but when trained } \\
\text { that this is the colour of blood, they will report it as blood } \\
\text { Interpretation in these specialties may need colour perception }(n=3) \\
\text { Experience may help; may learn to use other cues; may become competent over time }(n=5) \\
\text { They would have worked out how to overcome the difficulty, but there is no way to confirm it } \\
\text { I would be comfortable if they undergo training on how to overcome it ( } n=2) \\
\text { I don't know whether they can identify stained slides with experience (paediatrician with CCVD) } \\
\text { Depends on the particular test; most are done in automated analyzers }(n=4) \\
\text { Colorimetric tests may pose problems, unless they are machine read } \\
\text { Unless analysis of my report needs distinguishing colours, I will be okay with it }(n=2) \\
\text { Pathologists, hematologists, and radiologists may have limitations }(n=4) \\
\text { I am unsure because I have not come across any person with CCVD } \\
\text { Depends on the individual doctor; skills vary from person to person }(n=2) \\
\text { They would need to recheck or get opinion of peers before reporting }(n=2) \\
\text { Depends on type of deficiency (Forensic medicine specialist with CCVD) }\end{array}$ \\
\hline $\begin{array}{l}\text { treating physician had } \\
\text { colour vision deficiency }\end{array}$ & $\begin{array}{l}\text { Depends on what I am suffering from }(n=13) \\
\text { Because I do not know what a colour blind person can see }(n=2) \\
\text { There might be limitations; signs may be misinterpreted }(n=4) \\
\text { They may have mastered the technique even with CCVD }(n=4) \\
\text { Some doctors are careless even when they can see colours. I would prefer a thorough doctor with CCVD over a physician } \\
\text { who takes me for granted } \\
\text { Depends on type and extent of CCVD ( } n=2 \text {, including Forensic medicine specialist with CCVD) } \\
\text { They become equally competent over time; use various other criteria to diagnose }(n=4)\end{array}$ \\
\hline $\begin{array}{l}\text { treating surgeon had } \\
\text { colour vision deficiency }\end{array}$ & $\begin{array}{l}\text { Provided they can localize a bleeder, differentiate artery from vein }(n=4) \\
\text { I do not know what a colour blind person can see } \\
\text { Depends on experience and number of surgeries done with confidence }(n=2) \\
\text { They may master the technique even with CVD } \\
\text { Depends on degree and type of colour deficiency }(n=5 \text {, including Forensic medicine specialist with CCVD) } \\
\text { Depends on type of case, situation, and expertise }(n=4) \\
\text { Depends on individual doctor; they become equally competent over time }(n=3) \\
\text { Difficulties can be overcome with help of other members of the surgical team } \\
\text { Should be supervised before performing independent surgeries }\end{array}$ \\
\hline
\end{tabular}

were also brought out by the other respondents in our study; these are discussed below.

The fear of the naysayers was counterbalanced by those who believed that CCVD would not impact practice in their specialty because of the automation of tests and advanced monitoring equipment - some with audible signals; moreover, one could effectively focus on colour-independent signs and patterns to compensate for the CCVD. Most encouraging was their outlook that people with CCVD adapt to their deficiency and that their skills are honed through repetitive, reflective practice. This information is augmented by their belief (nearly half the respondents, including the three with diagnosed
CCVD) that, over time or with training, doctors with CCVD could learn to use colour-independent cues (like detailed history, brightness and contrast, close observation, touch, etc.) to avoid errors. Others also felt that people with CCVD have their own ways of perceiving colours and noticing colour changes which are different from those of colour normal individuals. Some seemed to understand that the type and degree of CCVD would dictate how much it affected practice. Five respondents, who had worked with doctors with CCVD, were particularly confident of their ability to manage competently. This belief mirrors that from around the globe where physicians - some of them with CCVD - write about ways of coping so as to maximise competence and minimise risk to patients (1- 
Table 4:

Reasons given by respondents for their comfort with their diagnostic or treating physician or their surgeon having CCVD

\begin{tabular}{|c|c|}
\hline I would be comfortable if my & Reason \\
\hline \multirow{10}{*}{$\begin{array}{l}\text { diagnostic report was signed } \\
\text { by a doctor with colour vision } \\
\text { deficiency }\end{array}$} & Colour perception is not the only criteria to determine capability of a doctor \\
\hline & We have never known the colour vision of doctors who prepare and sign reports $(n=2)$ \\
\hline & Provided the person has been certified by a competent authority \\
\hline & They do see colours, just perceive them in a different way \\
\hline & With repeated practice they can overcome the deficiency $(n=2)$ \\
\hline & Most things are automated now \\
\hline & Persons with CCVD can take the help of technicians and other colleagues $(n=3)$ \\
\hline & They can differentiate hues and shades \\
\hline & They'll do a more detailed assessment \\
\hline & They are competent enough to differentiate even with CVD $(n=2)$ \\
\hline \multirow{10}{*}{$\begin{array}{l}\text { treating physician had colour } \\
\text { vision deficiency }\end{array}$} & Colour perception is not the only criteria to determine capability of a doctor $(n=2)$ \\
\hline & Skills in other aspects would make up for colour blindness $(n=7)$ \\
\hline & Sign and symptoms and investigations also play an important role $(n=3)$ \\
\hline & If he is competent enough, colour vision does not matter practically $(n=3)$ \\
\hline & Provided the person has been certified by a competent authority $(n=2)$ \\
\hline & They do see colours, just perceive them in a different way \\
\hline & I don't think it will affect his clinical judgment (paediatrician with CCVD) \\
\hline & They are no different from doctors with normal colour vision \\
\hline & They'll know how to overcome the disability \\
\hline & With repeated practice and experience, they can overcome the deficiency $(n=3)$ \\
\hline \multirow{7}{*}{$\begin{array}{l}\text { treating surgeon had colour } \\
\text { vision deficiency }\end{array}$} & Colour perception is not the only criteria to determine capability of a doctor \\
\hline & $\begin{array}{l}\text { Surgeon treats according to history, clinical findings, and investigations, so colour deficiency will not hamper } \\
\text { treatment }(n=2)\end{array}$ \\
\hline & Will not make a difference to diagnostic or surgical skills (Paediatrician with CCVD) \\
\hline & $\begin{array}{l}\text { Surgeons with CVD can 'see' and identify blood as a shade of red and all other tissue colours also just like surgeons } \\
\text { with normal colour vision can; blood is so conspicuous }(n=3)\end{array}$ \\
\hline & $\begin{array}{l}\text { I know a very successful gastrosurgeon who is colour blind. According to him his colour blindness was never a hurdle } \\
\text { in his surgeries }\end{array}$ \\
\hline & With repeated practice they can overcome the deficiency \\
\hline & But the surgeon must be experienced (CCVD-unconfirmed Microbiologist) \\
\hline
\end{tabular}

$4,13,16)$. Also encouraging was the fact that some respondents with CCVD and CCVD-unconfirmeds (two paediatricians, one forensic medicine specialist, and one microbiologist) felt there would be no problem if a person with CCVD took up practice in their specialty. They could have been biased in favour of others with the condition; however, as shown earlier, the literature supports them.

\section{CCVD and medical practice}

To get an in-depth idea of how respondents really viewed the issue, we asked if they would be comfortable being tested/examined/operated on by a doctor with CCVD. Again, as mentioned earlier, at least half said they would not be comfortable when it came to their own health; the reasons they gave (Table 2) seem to centre around their belief that diagnostics and medical/surgical interventions were heavily dependent on an ability to distinguish colour differences. On the other hand, those who were unsure and those who were completely comfortable with the idea gave reasons that suggested they recognised the following with respect to doctors with CCVD (Tables 3 and 4, including some respondents with CCVD/CCVD-unconfirmed): the degree of deficiency is variable; the condition being congenital, people have adapted to a different way of seeing by the time they join medicine; repeated practice and attention to other details/ clinical cues and to symptoms and signs help; availability of sophisticated instruments and equipment precludes the need for excellent colour vision; and working in teams allows peer consultation in case of doubt. This is indeed the case as the literature shows $(1-3,8,13,16-18)$.

\section{The "safe" disciplines}

Table 5 suggests that there are many clinical disciplines (lower half of the list) that most respondents think are not likely to pose problems to a practitioner with CCVD. However, other disciplines are likely to be difficult for a person with CCVD: in order of greater to lesser difficulty, these are Ophthalmology, General surgery, Dermatology, Obstetrics and Gynaecology and 


\begin{tabular}{|l|c|c|c|}
\hline \multicolumn{4}{|c|}{$\begin{array}{c}\text { Table 5: } \\
\text { Specialties ranked according to the ones the 218 respondents felt a } \\
\text { doctor with CCVD would have difficulty practicing in }\end{array}$} \\
\hline $\begin{array}{l}\text { Specialty under } \\
\text { consideration }\end{array}$ & $\begin{array}{c}\text { Will have } \\
\text { difficulty } \\
\text { Total (\%) }\end{array}$ & $\begin{array}{c}\text { I cannot } \\
\text { say } \\
\text { Total (\%) }\end{array}$ & $\begin{array}{c}\text { Will NOT } \\
\text { have } \\
\text { difficulty } \\
\text { Total (\%) }\end{array}$ \\
\hline Pathology & 164 & 27 & 27 \\
& $(75.2)$ & $(12.4)$ & $(12.4)$ \\
\hline Microbiology & 145 & 28 & 45 \\
& $(66.5)$ & $(12.8)$ & $(20.6)$ \\
\hline Ophthalmology & 120 & 27 & 71 \\
& $(55.0)$ & $(12.4)$ & $(32.6)$ \\
\hline General Surgery & 115 & 27 & 76 \\
& $(52.8)$ & $(12.4)$ & $(34.8)$ \\
\hline Dermatology & 109 & 28 & 81 \\
& $(50.0)$ & $(12.8)$ & $(37.2)$ \\
\hline Biochemistry & 88 & 29 & 101 \\
& $(40.4)$ & $(13.3)$ & $(46.3)$ \\
\hline Forensic Medicine and & 85 & 27 & 106 \\
Toxicology & $(39.0)$ & $(12.4)$ & $(48.6)$ \\
\hline Obstetrics and & 85 & 27 & 106 \\
Gynaecology & $(39.0)$ & $(12.4)$ & $(48.6)$ \\
\hline Anatomy & 80 & 28 & 110 \\
& $(36.7)$ & $(12.8)$ & $(50.5)$ \\
\hline Otorhinolaryngology & 79 & 27 & 112 \\
& $(36.2)$ & $(12.4)$ & $(51.4)$ \\
\hline Radiology & 74 & 28 & 116 \\
& $(33.9)$ & $(12.8)$ & $(53.2)$ \\
\hline Orthopaedics & 73 & 28 & 117 \\
& $(33.5)$ & $(12.8)$ & $(53.7)$ \\
\hline Anaesthesia & 61 & 29 & 128 \\
& $(28.0)$ & $(13.3)$ & $(58.7)$ \\
\hline General Medicine & 59 & 29 & 130 \\
& $(27.1)$ & $(13.3)$ & $(59.6)$ \\
\hline Paediatrics & 58 & 29 & 131 \\
& $(26.6)$ & $(13.3)$ & $(60.1)$ \\
\hline Pental Surgery & 58 & 29 & 131 \\
& $(26.6)$ & $(13.3)$ & $(60.1)$ \\
\hline Pharmacology & 36 & 29 & 153 \\
& $(16.5)$ & $(13.3)$ & $(70.2)$ \\
\hline & 29 & 156 \\
& $(15.1)$ & $(13.3)$ & $(71.6)$ \\
\hline & 29 & 175 \\
& $(13.3)$ & $(80.3)$ \\
\hline & & 181 \\
& $(13.3)$ & $(83.0)$ \\
\hline
\end{tabular}

Otorhinolaryngology. Similarly, pre- and para-clinical subjects like Pathology and Microbiology could be problematic. Though some of the reasons our respondents gave are supported by the literature (see preceding paragraph), this list is based on the subjective opinion of practitioners and may not represent reality; moreover, two of the reasons they gave make lists such as this one redundant: the degree of deficiency is variable, and no one discipline is exclusively and entirely dependent on colour vision $(2,10)$.

To exemplify this, consider a few of the disciplines at the top of the "problematic" Table 5. The concerns of our participants with Pathology and Microbiology are understandable since both depend on special stains to an extent, which might be problematic if the stains fall in the colour spectrum that is affected; however, the disciplines depend even more on a sound knowledge of morphology $(8,14)$ and on the associated clinical history $(5,19)$. Moreover, the acumen can be strengthened with the use of filters that may help people with CCVD (18) and by sharing the diagnostic test results for peer corroboration (these days, this can be done virtually if the colour deficient diagnostician works in isolation) (8). Biochemistry is lower down in the list of undesirable specialties, probably because respondents believed that automation of biochemical tests makes colour vision redundant.

Ophthalmology and General surgery are the next two specialties in the list. For ophthalmologists with a severe deficiency, problems may arise when it comes to detecting pigment versus blood in a fundus examination, although this differentiation can be aided with the red-free filter available in the ophthalmoscope (16). There may still be difficulty in noticing the colour of a bruise and colour changes of the conjunctiva or sclera in conjunctivitis, anaemia, or jaundice; however, a high index of suspicion based on the history and other findings can circumvent errors. Many surgical interventions on the anterior segment involve minimal to no bleeding (cataract surgery, especially phacoemulsification, and corneal laser procedures, for example), allowing eye surgeons with CCVD to flourish in these sub-specialties. As reported by an optometrist with CCVD and others, it is entirely possible to choose an area of ophthalmology in which to practise safely: one that does not depend on a critical ability to discriminate between colours $(16,20)$. Though our respondents felt it would need good colour discrimination, general surgery has not been reported in the literature as being a problem for people with CCVD. Apart from a difficulty in detecting bile or blood in vomitus, or blood in stools, no other difficulty has been attributed to CCVD. Indeed, taking an example from real life, a well-respected and prolific surgeon with CCVD who is credited with establishing the field of gastrointestinal surgery in the country decades ago has openly shared the fact that he has $\operatorname{CCVD}(21,22)$. Apparently, an understanding of one's particular deficiency, followed by practice to mitigate its influence on decision-making and use of other cues, including a knowledge of anatomy and good illumination, is the way to practise safely $(1,3,20)$. The strategies discussed in this section could be broadly applied to all surgical disciplines. In addition, with the advent of robotic technology to assist surgeons, where the surgical field is displayed on a computer screen, perhaps filters can be inbuilt to help compensate for colour deficiency. With awareness, with practice, and with the use of technology, CCVD could well turn out to be nothing more than a "mild inconvenience" (8). The fact that CCVD is not classified as a 
specified disability in The Rights of Persons with Disabilities Act, 2016, reinforces this concept (23).

In the field of Dermatology, as in other medical specialties, detecting the presence or defining the extent of erythema could be a problem; however, paying attention to symptoms, to the morphology of the lesion and its location, and to the surface of the skin, using filters and good illumination, and asking for corroboration, sometimes even from the patient, are all ways to minimise errors $(7,8,16,18)$.

\section{Convincing trainers to provide reasonable accommodation to learners with CCVD}

The evidence - discussed in the preceding paragraphs - in support of safe practice by doctors with CCVD, who are aware of the condition and take care to compensate for it, may give a direction to the opinions of those who are unsure if training and experience could help. The key is to be aware of the colour deficiency and to learn to compensate for it. Learners with CCVD do make more errors under study conditions than those with normal colour vision $(1,8,15,17)$; however, it may not directly translate into having an adverse impact on diagnosis and treatment at the bedside or in the operation theatre $(5,19)$. After all - and this needs to be understood - even people with normal colour vision make errors (1); also, it is recognised that medical errors occur when multiple factors converge (24). During the medical course, learners could be encouraged to explore their limitations, if any; be given compensatory time where needed (say 15 minutes extra per hour for histology exams); allowed the use of colour vision aids like filters and screens; and be helped to find other cues/creative ways to compensate for the CCVD. This accommodation, made within reasonable limits, would be of enormous help in building confidence, and it may prevent errors.

Potential accommodations include the use of gray-scale microscopes; assistive technology with Daltonising algorithms, Chromagen and true colour-display technology; close observation and cross checking; using green instead of red laser pointers; and ensuring black coloured arrows and pointers on lecture slides, among others (25).

\section{Following an ethical path where health practitioners with CCVD are concerned}

The data shows that the specialisation options for a medical student with CCVD are not as limited as one might imagine; however, the disparity in the views within departments means that, in the absence of policy guidelines, whether students ultimately get to join the specialty of their choice depends on who is sitting at the decision-making table. If it is a person who believes that colour is not only a critical but also a nonnegotiable requirement for practice in that specialty, then the learner is doomed. This, indeed, happens; two of the authors (UD and SS) have been approached by physicians with CCVD who were denied residency jobs (personal communications). Contrast this with a decision-maker who believes that colour is only one of many tools available to a practitioner; that non-colour-dependent cues are equally important; and that learners with CCVD have mechanisms in place, from birth onward, that allow them to function fairly well in a way that is different from the behaviour of people with normal colour vision. In such a case, the learner would be able to specialise in the subject of his choice. It seems unfair to base other peoples' careers on one's arbitrary beliefs, but this does happen. Members of admissions committees, of medical boards, and of job selection committees are not entirely to blame since the country does not yet have a clear-cut policy on which specialties a person with CCVD can train for or work in. In the absence of guidelines, members must use their own judgement - but as we can see from our own data, the decisions could go either way.

How do we decide who is right? Undeniably, patient safety is important, as highlighted by some of the naysayers, but where is the evidence that doctors with CCVD endanger patients? On the contrary, there are reports of eminent and competent doctors who, incidentally, also have CCVD $(14,21,22)$. When we speak of potential limitations due to CCVD, do we stop to consider the advantages that colour deficiency may bestow (26)? Do we consider how much benefit would accrue from making a reasonable accommodation for learners until they learn to navigate the deficiency as applied to the practice of medicine? After all, they have already been navigating a world that is geared for colour normal individuals and not for universal access. And they have been adapting to the requirements of such a world since the day they were born, compensating in cognitive and several other ways for the deficiency $(13,27)$. Is it fair to consider their way of seeing colours as abnormal and hence to suggest it be treated? While the Medical Council of India is silent on the matter of treatment, the Indian Nursing Council has declared that such students could join the nursing course provided that they wore colour corrective contact lenses or spectacles (28). The decision may not be without its own ethical dilemma. Persons who have spent the first two decades or so of life adjusting to a certain way of seeing colours, may find that corrective lenses impact their learning because now the colours they see are completely new to them. It is important to understand that they did not become colour blind the day they were tested, but have always been that way since birth. That is their normal, they grew up with it, their brains developed around it. A new spectrum may confuse and shock the brain (27). Regulators need to determine if it would be fair to force learners to take on a whole new colour spectrum when, for all we know, they may make no errors with their usual spectrum. Far from helping them, colour corrective lenses and spectacles may be counterproductive and may remove all the advantages they have acquired with respect to other senses like touch and other clues like hue and luminescence. Besides, existing colour-corrective glasses are costly and bulky, and do not lend themselves to use with other vision correcting lenses (29). Perhaps, instead of enforcing the use of aids, the aid could be suggested, and teachers and the individual learner could collaborate to decide if the aids help or hinder. Keeping 
in mind the variability of the colour spectrum in each person with CCVD, it is prudent to appreciate that one size may not fit all. Without the dominance of colour, all the other attributes are enhanced (surface, texture, transparency). This could be an advantage - would doctors with CCVD be better placed to pick up subtle differences between normal and abnormal? We don't know. Who are we to decide? Who is to say that, when colournormal providers make mistakes, it is nothing to do with the fact that their colour dominance distracts them from seeing other important things? It is worth reproducing here what some of our respondents said:

"Some doctors are careless even if they can see colours. I would prefer a thorough doctor with CCVD to a physician who takes me for granted."

"Color perception cannot be the only criteria to determine capability of a doctor."

"Have undergone umpteen diagnostic tests and radiological investigations since birth - and am still alive. We never tried to find out who all were color blind - possibly there were a few."

\section{The voices of doctors with CCVD}

The only way to answer these questions is to study more doctors with CCVD - the best way to do that is by having more doctors with CCVD across the board in the healthcare field and by removing fear of stigma so that they share their experiences. If our participants are to be believed, their colleagues with CCVD posed no risk to patients. It would be best if we could hear from more doctors who are colour blind. They are welcome to share openly; however, they might inadvertently expose themselves to stigma and to a possible witch-hunt where they could selectively be asked to prove their competency. Perhaps an anonymous study can be designed to figure this out. Certainly, as mentioned earlier, we had hoped to hear from more doctors with CCVD, but that did not happen for the reasons mentioned previously. We request healthcare providers with CCVD to reach out to us.

\section{Strengths and limitations of the study}

The sample size of this study is large enough to warrant generalisation of its results across the country. Participants had enough post-specialisation experience to make their responses valuable. Even though only a few of the participants themselves had CCVD, we had representation from PP, as also from MM and SS specialties, allowing a glimpse of how each broad group viewed the dilemma of CCVD in medicine. On the flip side, this was an online, anonymous survey and may not have been able to capture as much information as a faceto-face interview may have done. A focus group discussion might have helped determine lived experiences, experiences with ableist microaggression from peers and faculty, and adjustments made over time by participants with CCVD. Some participants may not have had enough knowledge about CCVD and may have given generic responses; however, the responses also indicated the reverse - that a number of respondents were aware of the nuances of CVD. Being anonymous, we have no way to reach out to the participants with CCVD for their degree of deficiency or for follow-up discussions; however, we are hopeful that those who wish to share their experiences and their learning and coping mechanisms will reach out to us so as to settle this matter once and for all.

\section{Conclusions}

Our respondents varied in their opinions with respect to people with CCVD in medicine; the insights they provided were useful in formulating an advisory. For the time being, until we learn more about how providers' CCVD impacts patient care in each specialty, CCVD should not be a barrier to practising in any specialty of medicine. Rather than blocking medical students from joining a postgraduate course that they are otherwise eligible for, they could be encouraged, while still undergraduates, to explore their particular grade of CCVD for any difficulty it could cause during practice. They need to be open to sharing, and teachers and peers should be open to supporting them and providing reasonable accommodation so that they find ways to compensate for their particular colour spectrum. Learning this in a supported environment can prepare them for safe care in real life when they work with patients. This is the responsibility of the faculty departments, institutions, regulatory bodies, and governments, keeping in mind the rights of people with CCVD to practise medicine within the realms of patient safety. Depending on how confident they feel after training, they should make informed decisions about which specialty they can be most comfortable practising safely in. There is a need to train faculty in the tenets of reasonable accommodation and also to provide opportunities to undergraduate learners with CCVD to shadow physicians in the specialty of their choice before making the decision to train in it.

\section{Funding support: None.}

Conflict of interest: Dr Upreet Dhaliwal has first degree relatives with CCVD. They are not medical practitioners. Their non-medical career choices, in their own words, were not influenced by the CCVD, but were dictated by their areas of interest.

\section{References}

1. Dhingra R, Rohatgi J, Dhaliwal U. Preparing medical students with congenital color vision deficiency for safe practice. Natl Med J India. 2017 Jan;30:30-5.

2. Campbell JL, Griffin L, Spalding JAB, Mir FA. The effect of abnormal color vision on the ability to identify and outline colored clinical signs and to count stained bacilli in sputum. Clin Exp Optom. 2005 Nov;88(6):376-81.

3. Campbell JL, Spalding AJ, Mir FA, Birch J. Doctors and the assessment of clinical photographs--does color blindness matter? Br J Gen Pract. 1999;49(443):459-61.

4. Campbell JL, Spalding JA, Mir FA, Birch J. Doctors and the assessment of blood glucose testing sticks: does color blindness matter? Br J Gen Pract. 2000 May;50(454):393-5.

5. Spalding JA. Medical students and congenital color vision deficiency: unnoticed problems and the case for screening. Occup Med (Lond). 1999 May;49(4): 247-52.

6. Olson IA. The use of color filters by students with congenital color defects in the learning of histology. Med Biol Illus. 1971 Jan;21(1):52-3.

7. Spalding JAB, Cole BL, Mir FA. Advice for medical students and practitioners with color vision deficiency: a website resource. Clin 
Exp Optom. 2010 Jan;93(1):39-41. Available from: https://www.doi. org/10.1111/j.1444-0938.2009.00434.x

8. Goudie RB. Color deficient vision should not prevent a career in histopathology. BMJ.1998 Jun 6;316(7146):1750.

9. Delhi High Court. Dr. Kunal Kumar vs Union Of India (Uoi) And Ors. 2002 Nov 21 [cited 2020 Jun 19]. Available from: https://indiankanoon.org/ doc/775659/

10. Spalding J. Confessions of a color blind physician. Clin Exp Optom. 2004;87(4-5):344-9.

11. Spalding JA. The doctor with an inherited defect of color vision: effect on clinical skills. Br J Gen Pract. 1993 Jan;43(366):32-3.

12. Dhaliwal U. 'Reasonable accommodation' for medical professionals with congenital color vision deficiency. Natl Med J India. 2018 MarApr;31(2):65-6. Available from: https://www.doi.org/10.4103/0970258X.253161

13. Chakrabarti S. Psychosocial aspects of color vision deficiency: Implications for a career in medicine. Natl Med J India. 2018 MarApr;31(2):86-96. Available from: https://www.doi.org/10.4103/0970258X.253167

14. Rubin LR, Lackey WL, Kennedy FA, Stephenson RB. Using color and grayscale images to teach histology to color-deficient medical students. Anat Sci Educ. 2009 Mar-Apr;2(2):84-8. Available from: https://www.doi. org/10.1002/ase.72

15. Spalding JA. Color vision deficiency in the medical profession. $\mathrm{Br} J \mathrm{Gen}$ Pract. 1999 Jun;49(443):469-75.

16. Cockburn DM. Confessions of a color blind optometrist. Clin Exp Optom. 2004 Jul;87(4-5):350-2.

17. Poole CJ, Hill DJ, Christie JL, Birch J. Deficient color vision and interpretation of histopathology slides: cross sectional study. BMJ. 1997;315(7118):1279-81.

18. Simunovic MP. Color vision deficiency. Eye. 2010;24(5):747-55. Available from: https://www.doi.org/10.1038/eye.2009.251

19. Campbell JL, Spalding JAB, Mir FA. The description of physical signs of illness in photographs by physicians with abnormal color vision. Clin Exp Optom. 2004 Jul;87(4-5):334-8. Available from: https://www.doi. org/10.1111/j.1444-0938.2004.tb05063.x

20. Spalding J. Practising medicine when you have color blindness. BMJ. 2004;329:s126. Available from: https://www.bmj.com/ content/329/7468/s126

21. Hajra N. Color blind people can now become doctors, as India ends decades-old practice. CIMS Today [Internet]. 2017 Aug 4 [cited 2020 Jun 19]. Available from: https://today.mims.com/color-blind-people-canbecome-doctors-as-india-ends-decades-old-practice

22. Nagarajan R. 'Color blind pupils should be allowed to study med'. The Times of India [Internet]. 2017 July 10 [cited 2020 June 21]. Available from: https://timesofindia.indiatimes.com/india/color-blind-pupilsshould-be-allowed-to-study-med/articleshow/59519851.cms

23. Ministry of Law and Justice, Government of India. The Rights of Persons with Disabilities Act, 2016. [cited 2020 Jun 21]. Available from http:// legislative.gov.in/actsofparliamentfromtheyear/rights-personsdisabilities-act-2016

24. Rodziewicz TL, Hipskind JE. Medical Error Prevention. Updated 2020 May 5. In: StatPearls. Treasure Island (FL): StatPearls Publishing; 2019 [cited 2020 Jun 19]. 1-22 p. Available from: http://www.ncbi.nlm.nih.gov/ pubmed/29763131

25. Serrantino J, Meeks LM, Jain NR, Clifford GC, Brown JT. Accommodations in didactic, lab, and clinical settings. In: Meeks LM, Jain NR, editors. The guide to assisting students with disabilities: equal access in health science and professional education. New York: Springer Publishing Company. 2015 Aug 13:59-88.

26. Davidson GA. Color blindness in physicians. JAMA. 1943 May 29;122(5):332. Available from: doi:10.1001/jama.1943.02840220064025

27. Sacks O. The Island of the Color-blind. London: Picador; $2012.311 \mathrm{p}$.

28. Bombay High Court. Ravikant Amarsing Naik v. State Of Maharashtra And Others. 2019 Jan 10 [cited 2020 Jun 19]. Available from https:// www.casemine.com/judgement/in/5d9199b6714d587fe94e8a0f

29. Badawy AR, Hassan MU, Elsherif M, Ahmed Z, Yetisen AK, Butt H. Contact lenses for color blindness. Adv Healthcare Mater. 2018; 7(12):e1800152. doi:10.1002/adhm.201800152

\title{
Admission of persons with disabilities into nursing and midwifery courses: Progress made by the Indian Nursing Council
}

\author{
HAREESH ANGOTHU, SHARAD PHILIP, REVATHI SOMANATHAN, KRISHNAREDDY SHANIVARAM REDDY, DEEPAK JAYARAJAN, KRISHNA PRASAD \\ MULIYALA, JAGADISHA THIRTHALLI
}

Authors: Hareesh Angothu (hareesh.angothu@gmail.com), Associate Professor of Psychiatry, NIMHANS, Bengaluru, 560029 INDIA; Sharad Philip (sharadphilipdr@gmail.com),Senior Resident in Psychiatric Rehabilitation Services, NIMHANS, Bengaluru, 560029 INDIA; Revathi Somanathan (Revathi.somanathan@gmail.com), Doctoral Scholar in Psychiatric Rehabilitation Services, NIMHANS, Bengaluru, 560029 INDIA; Krishnareddy Shanivaram Reddy (shanivaramreddyk@gmail.com),Assistant Professor of Psychiatric Social Work, NIMHANS, Bengaluru 560029 INDIA; Deepak Jayarajan (deepak.jayarajan@gmail.com)Associate Professor of Psychiatry, NIMHANS, Bengaluru 560029 INDIA: Krishna Prasad Muliyala (krishnadoc2004@gmail.com), Additional Professor of Psychiatry, NIMHANS, Bengaluru 560029 INDIA; Jagadisha Thirthalli (jagatth@yahoo.com), Professor of Psychiatry, NIMHANS, Bengaluru. 560029 INDIA.

To cite: Angothu H, Philip S, Somanathan R, Reddy KS, Jayarajan D, Muliyala $\mathrm{KP}$, Thirthahalli J. Admission of persons with disabilities into nursing and midwifery course: Progress made by the Indian Nursing Council. Indian J Med Ethics. 2020 Oct-Dec; 5(4)NS:277-85.DOI:10.20529/IJME.2020.111.

Manuscript Editor: Olinda Timms

Peer Reviewers: Pragna Rao, Satendra Singh

(c) Indian Journal of Medical Ethics 2020

\section{Abstract}

India's Persons with Disabilities Act, 1995 (PWD Act, 1995) mandated a minimum enrollment reservation of $3 \%$ for persons with disability ( $P w D s)$ across all educational courses supported by government funding. Following this, the Indian Nursing Council (INC) issued regulations limiting such an enrollment quota to PwDs with lower limb locomotor disability ranging between $40 \%-$ $50 \%$. The Medical Council of India (MCI) also restricted admissions under the PWD category to PwDs with a lower limb locomotor disability to comply with the Act. The Rights of Persons with Disabilities (RPwD) Act, 2016, which replaced the PwD Act, 1995, raised the minimum reservation to $5 \%$ for all government-funded institutions of higher education and extended this reservation to PwDs under 21 different clinical conditions, rather than the seven conditions included under the PwD Act, 1995. Following the enactment of the RPwD Act, 2016, the $\mathrm{MCl}$ issued regulations that allowed PWDs with locomotor disability and those with a few other types of disabilities in the range of $40 \%-80 \%$, to pursue graduate and postgraduate medical courses, while the INC has 